\title{
Understanding Older Adults' Resilience During the Brisbane Floods: Social Capital, Life Experience, and Optimism
}

\author{
Lauren Brockie, MS; Evonne Miller, PhD
}

\section{ABSTRACT}

Objective: The purpose of this study was to explore how social capital or the impact of life and previous disaster experience facilitated resilience in older adults who experienced the 2011 and 2013 floods in Brisbane, Australia.

Methods: Data were drawn from in-depth interviews of 10 older adults from Brisbane who were evacuated in both the 2011 and 2013 floods. A combined qualitative approach drawing from the methods of constructivist grounded theory and narrative inquiry was applied and the data were analyzed by using (inductive) line-by-line and axial coding.

Results: The narratives of the older adults revealed a strong theme of resilience linked to social capital (bonding, bridging, and linking) and previous disaster experience. The results reflected the changing face of disaster management strategies and sources of social capital.

Conclusions: Changes in disaster management polices (toward self-reliance) and more formalized sources of social capital highlight the need to build strong and healthy resilient communities that are capable of positively recovering from natural disasters. The results from this research emphasize the importance of initiatives that enhance social cohesion, trust, and social capital within local communities. (Disaster Med Public Health Preparedness. 2017;11:72-79)

Key Words: Brisbane floods, disasters, older adults, resilience, social capital

$\mathrm{T}$ Theoretical and empirical disaster research typically highlights a long and traumatic history of adverse effects from disasters; at first glance, a natural disaster appears to negatively impact all affected individuals. ${ }^{1}$ For example, over the past 30 years in Australia, natural disasters have affected over 16 million people, caused almost AU $\$ 40$ billion in damage and killed close to 1000 people, with climate change predicted to only increase the frequency and severity of these disasters. ${ }^{2}$ Critically, the literature suggests that not all victims of these disasters will be impacted equally. An individual's ability to cope with a disaster varies significantly depending on the type, location, and duration of the disaster, as well as the unique social, economic, environmental, and demographic vulnerabilities of the population in harm's way.

While disasters tend to have negative impacts on all involved, research suggests that older adults tend to be disproportionately vulnerable to both the short- and long-term consequences of disasters. ${ }^{3}$ Recent disasters illustrate this: the death rate during the Paris heat wave in 2003 was highest for those over 70 years of age; $^{4}$ the Aceh (Indonesia) tsunami in 2004 recorded the highest death rate for those over 60 years of age; ${ }^{4}$ when Hurricane Katrina hit New Orleans in 2005, $71 \%$ of people killed were aged 60 years and older; ${ }^{5}$ and of the 15,884 lives lost in the 2011 Japanese Tsunami, $77 \%$ of those were elderly. ${ }^{5}$ Research suggests that a combination of factors associated with increased age makes older adults more vulnerable, including poor health (physical/psychological), poverty or low income, loss of independence, physical living environment, geographical location, and social resources. $^{3}$ Despite these known vulnerabilities, an older adult's level of risk is further raised by Australia's self-reliance (or "self-help") disaster management policy, which emphasizes that all individuals should be equally capable of being responsible for themselves when preparing for and recovering from a natural disaster. ${ }^{6}$ Therefore, contemporary empirical disaster research needs to facilitate the identification of these vulnerabilities, while also exploring protective and resilience factors relating to increasing an older adult's self-efficacy during future disasters.

Resilience has been defined as a dynamic process (involving beliefs, experiences, attitudes, and behaviors) of maintaining successful adaptation following exposure to potentially traumatic life events. ${ }^{7-9}$ It can be seen in those individuals who "bend rather than 
break" and return to (or exceed) their prior level of psychological, physical, emotional, and social functioning following the trauma or natural disaster. ${ }^{7-9}$ Research has found that older adults tend to display greater levels of resilience in response to trauma than do younger persons. ${ }^{10}$ One factor contributing to older adults' resilience is the influence of past behavior and experiences, such as prior trauma and disaster experiences. Recent research suggests that communitydwelling older adults with prior disaster exposure tend to be more resilient, have better psychological adjustment, and experience less emotional distress following a disaster. ${ }^{11-13}$ Ferraro $^{14}$ termed this the stress "inoculation hypothesis," arguing that older adults' prior exposure to natural disasters protected them from strong negative emotional reactions to subsequent disasters. This apparent protective factor has been linked to the wide range of lifetime experiences that older adults can draw upon as coping resources to best support them and impact on the overall resilience of their community. ${ }^{15}$

Along with life experience, research typically identifies social connections as an important factor predicting both individual and community resilience during and after a disaster. ${ }^{16}$ Social capital, defined as one's capacity to mobilize resources based on their social relationships and position within the social structure, ${ }^{17}$ has been found to positively influence resilience. For example, diverse research by Aldrich ${ }^{18}$ examining the post-disaster resilience and recovery of $4 \mathrm{com}$ munities (Tokyo after the 1923 earthquake, Kobe following the 1995 earthquake, Tamil Nadu after the 2004 Indian Ocean Tsunami, and New Orleans after Hurricane Katrina) found that communities with robust social capital were better able to quickly disseminate information, provide financial and physical assistance, and facilitate a more successful overall recovery.

Furthermore, Fussell ${ }^{19}$ reported that older adults with lower levels of social capital were more vulnerable during a natural disaster owing to infrequent communication, low levels of economic support, feelings of isolation, and limited access to shared information and channels of recovery. During a disaster, isolated individuals with few social ties and lowered social capital are less likely to be rescued, seek medical help, and take preventative action, such as evacuating and receiving assistance from others. ${ }^{20}$ Researchers typically separate social capital into 3 main types: bonding (close connections among similar individuals, such as family, friends, and neighbors), ${ }^{21,22}$ bridging (relationships among people who differ in class, geography, or age, often developing from involvement in civic, political, and sports or interest organizations), ${ }^{23}$ and linking (relationships with institutions that have relative power in society, through providing access to services or resources) capital. ${ }^{16,23,24}$

Strong bonding capital, the most commonly available social resource from friends and family, can provide significant emotional support and practical assistance in times of disaster, allowing older adults to receive warnings, prepare, locate shelters and supplies, and obtain immediate aid and recovery assistance. ${ }^{16}$ Both Fussell ${ }^{19}$ and Durrant ${ }^{25}$ have reported that bonding capital was instrumental in helping vulnerable people evacuate before and after Hurricane Katrina, highlighting the fact that those without strong bonding capital were among the last to evacuate and were the most dependent on formal services to provide transportation, shelter, food, clothing, and medical attention. Strong bridging capital has been shown to provide opportunities and information on how to access resources that assist with long-term recovery, ${ }^{16}$ with ties to social organizations providing access to support through institutional channels (eg, a church collecting money for families in need). While bonding and bridging social capital often foster resilience and act as a fragile safety net during disasters, linking social capital (connecting regular community members with those in power) is a critical yet under-researched resilience resource. In the only published study reviewing linking capital and resilient outcomes, Nakagawa and Shaw ${ }^{26}$ found a positive relationship between linking social capital and recovery from the Gujarat earthquake.

Social capital may be one of the missing links that explains the differences between resilient and nonresilient older adults who experience the same disaster but have vastly different outcomes. Despite the evidence about its efficacy, to date, disaster management research has not yet fully explored the role of social capital or the impact of life and previous disaster experience in facilitating resilience. Given the limited literature on older adults' disaster experience, and the lack of any published research in this field relating to the 2011 Brisbane floods, this research explicitly addressed this knowledge gap, exploring older adults' resilience and experience of bonding, bridging, and linking social capital during the 2011 and 2013 floods in Brisbane, Australia.

\section{METHODS}

Given the limited literature in this area, a combined qualitative approach drawing from the methods of constructivist grounded theory $(\mathrm{CGT})^{27}$ and narrative inquiry ${ }^{28}$ was used. The narrative inquiry methods helped to provide a rich understanding of the participants' experiences, whereas the systematic analytical procedures developed in CGT facilitated cross-case analyses of the study themes, with previous research highlighting the theoretical and methodological complementarity of these approaches. ${ }^{29}$

\section{Case Study Location and Flood Events}

The case study location was the city of Ipswich, located approximately 45 minutes west of Brisbane, the state capital of Queensland, Australia. Ipswich is located on the Bremer River in the Brisbane River catchment area, spans an area of $1090 \mathrm{~km}^{2}$, and has a population of 190,000 , with $14 \%$ aged 65 years and older. $^{30}$ In January 2011, three-quarters of Queensland was declared a disaster zone after the second 
highest flood of the last 100 years resulted in the forced evacuation of thousands of people from over 70 towns and cities. ${ }^{31}$ There was major flooding through most of the Brisbane River catchment area when the Brisbane River peaked at $19.25 \mathrm{~m}$, with the most severe impacts on the Lockyer and Bremer (Ipswich) catchments, where numerous flood height records were set and over 3000 properties were inundated. ${ }^{31}$ Only 2 years after the devastation of the 2011 floods, Ipswich was again impacted by another significant flood in early 2013 following rainfall associated with a tropical cyclone. These floodwaters impacted over 600 properties in the region, affecting more properties near creeks as the result of backflow flooding and causing significant bank erosion and damage to roads and crossing infrastructure and many agricultural areas. ${ }^{32}$ These floods impacted all members of the population-men and women, young and old — with equal devastation and destroyed infrastructure, limited communication avenues, led to power outages, restricted health services, and strained social connections. The present research focused on the impact of these floods on 10 older residents.

\section{Participants}

In-depth interviews were conducted with 10 older Ipswich residents ( 6 women and 4 men) who were evacuated from their homes during both the 2011 and 2013 Brisbane floods (6 also experienced the 1974 floods and 2 the 1955 floods). After the 2011 flood, 4 were out of their homes for less than 1 week, and the remaining 6 were displaced for over 7 months (ranging from 7.5 months to 1 year). With an average age of 73 years (ranging from 67 to 83 years), these older residents all lived independently in detached housing; 9 were homeowners and 1 rented. All had lived in their current homes for over 15 years and had adult children (average of 3.5 children each, ranging from 2 to 7 children). Two were widowed and the rest were married ( 2 were interviewed as a married couple).

\section{Procedure}

After obtaining formal ethical clearance from the University Human Research Ethics Committee, participants were recruited through a nonprobability snowball sampling approach (personal contacts, word of mouth, industry contacts, and radio interviews) and a targeted mailing to the 356 houses listed in the 2011 Ipswich flood map. Interested older residents were instructed to contact the researcher and were screened by telephone to ensure that they met 3 key inclusion criteria: aged over 65 years, lived independently in their own home, and evacuated in both the 2011 and 2013 Brisbane floods. Participants were allocated an interview time and mailed an information package. Standard best practice ethical protocols were followed. Participants were interviewed in person in their own homes by the first author (a registered psychologist) and interviews ranged in length from 60 to 190 minutes. Consistent with the CGT and narrative inquiry approaches, interviews commenced with a single open-ended question, "So, tell me about your experience with the Ipswich floods," followed by careful probing and individually tailored questions assessing flood preparations, impact (immediate and ongoing), emotional and physical health, social support, and recovery. All interviews were audio-recorded and transcribed verbatim by the first author. Interviews took place 2 years after the 2011 flood disaster (and a couple of months after the 2013 flood). Therefore, a pre-interview questionnaire, verbal prompts, and memorabilia (selected by the participants) were utilized as memory prompts. However, recall did not appear to be an obvious problem as many of the participants offered vivid memories of all floods (including of the 1974 floods from almost 40 years prior).

\section{Analysis}

Both authors independently listened to the interviews and analyzed transcripts using a CGT and narrative inquiry approach to examine and document individual stories in deep detail. ${ }^{28}$ Transcripts were read repeatedly with a focus on older adults' meanings, discussion, and understanding of resilience. The authors used the comparative method of $\mathrm{CGT}^{27}$ to undertake open (inductive) line-by-line coding, followed by a round of axial coding, reviewing the coding scheme and categories until consensus was obtained. The design of this study purposely incorporated several strategies to enhance the trustworthiness of the findings, including a thorough literature review to identify knowledge gaps, reflexivity between researchers (eg, regular analysis meetings), and prolonged engagement with the data. These strategies enhanced the study's analytical rigor, trustworthiness, and credibility, thus enabling critical review, reflection, and interpretation of the data and emerging themes. Finally, in an attempt to ensure authenticity, participants were offered the opportunity to review their final transcripts. Preliminary findings were validated through feedback during the interview process, and multiple exact quotes from the raw data were included in the analysis to enable readers to judge for themselves the accuracy of our analysis. ${ }^{27,28}$

Despite the participants together representing the phenomenon of interest (floods) in its real-life context, it cannot be ignored that the sample size was small $(\mathrm{N}=10)$. However, Charmaz ${ }^{27}$ suggests that the data generation process for CGT studies involves a diversity of data generated from a minimum of 10 participants. However, while the sample size does limit our ability to make generalizations, the geographical location of this flood area is similar to other geographical locations in Australia and worldwide, which suggests that the results may be of use relating to risk of similar events. Furthermore, these participants volunteered to take part in this study; therefore, a response bias may exist toward those older adults who are high functioning and able to fully engage in the research. It is likely that nonengaged participants could have reported significantly different experiences. Before the presentation of the results, it is important to note that this article reports only the 
experiences of 10 older community-dwelling flood survivors and does not explore the experiences of other different sociodemographic groups (eg, younger people, ethnicities, retirement-home-living older adults, etc). However, while the experiences described are those of older adults, other residents of Ipswich may have also had similar flood experiences.

\section{RESULTS}

Analysis of the data revealed a strong narrative of resilience, with these older residents describing how whatever happened, they (as both individuals and communities) would cope and adapt as required. The majority chose to view themselves as survivors rather than as "victims" of the floods, explaining that they made a choice to persevere rather than give into despair. As one person explained, "my philosophy is you just carry on anyway... [take the] ups and downs." This resilience narrative was typified by 3 key themes, which will be discussed in turn: social capital, previous disaster experience, and sources of support.

\section{Resilience Theme 1: "They came from everywhere... beautiful to be an Australian" - Social Capital During the Disaster}

While participants described various levels of support and capital, most emphasized the value of bonding social capital and their personal networks as critical aspects of their resilience. For some this network influenced whether they evacuated, as this was the only source of information they trusted, or in some cases had access to. Friends and family helped them gather information, make plans, survive the flood event, and recover, providing critical physical, emotional, and financial support. For example, one older couple recalled how their daughters actively engaged with and supported them during the whole event. The wife spoke about the support from her family who "just love to help, they are willing to come down and help," while her husband praised friends, noting that "it's not what you know, it's who you know. If you've got friends who are willing, then that's all you need." As families, friends, and neighbors came together to cope successfully, many of these older residents felt a new sense of belonging to and being valued by their local community. For example, one female participant fondly recalled organizing a barbeque at the local park to feed "June's [pseudonym] Army," approximately 25 friends and family who responded to a call for help on her daughter-in-law's Facebook page. Participants reflected on the changing times of network communication, stating that they had made individual phone calls for assistance, while younger family members used mass social media to recruit help.

While the overwhelming narrative was one of support from bonding networks, approximately one-third of the older adults felt isolated and unsupported. As is common with natural disasters, some had access to their normal bonding networks cut owing to the very nature of the flood event (eg, roads closed, telecommunication difficulties). A common sociodemographic trait that these isolated participants shared was that, compared to the other participants, they were all separated (or widowed) from their children's other parent. One spoke of her feeling of isolation when she found out about the flooding situation, her long 2-hour drive to assess her home, the rush to attempt to pack up her possessions, and her growing realization that she was on her own during the entire process with her 2 sons (her only source of social capital) being unable to help her on the day as they were helping their father who was also impacted. Those who reported low bonding social capital described efforts to cope on their own, including a longing for some sense of support from their community or officials.

Participants also described a system of bridging and linking networks in which people provided and shared information, supplies, and resources, recalling the kindness and generosity of strangers from the local community. One woman shared the story of a stranger who appeared during the flood event and provided her with a simple cup of tea-an act of kindness that she reports has stuck with her. Many shared positive experiences of the community spirit evident in flood cleanup and recovery, with both local and nonlocal residents assisting. As one participant explained, "I couldn't get back to sleep because I was so excited about the wonderful community spirit." Some participants felt so supported by this extended bridging capital that they were turning away strangers offering assistance. One lady recalled the buses of people arriving and walking the streets looking for those needing help, and her family regularly waving them on saying, "we're alright, keep on going." Those who reported low bonding capital also reported limited involvement within the wider community, especially as they were now retired with no work or social commitments linking them with the neighborhood. One described feeling forgotten by the community, stating, "no... didn't see anybody...(we were) a forgotten island...." Regardless of their bonding or bridging networks, the majority of interviewed residents (7 of 10) felt let down or disappointed with the level of assistance and "ground time" put in by local government representatives. One summarized his feelings on the matter by saying, "they [officials] show their face for the TV cameras and newspapers, then they piss off-never to be seen again," whereas another described the limited support as "short-term" and "nothing but lip service." This linking social capital was consistently reported as being noticeably absent after the disaster.

\section{Resilience Theme 2: "Just another hurdle" —Drawing on Previous Disaster Experience}

To their surprise, participants found that they had retained and could put to use much of the knowledge and skills they had developed over their lifetimes. Many shared stories of previous adversities that they had overcome (eg, fire, family 
or friends' death, marriage separation, and war), describing an "if I can get through that, then I can handle a flood" approach. As one explained in a matter-of-fact way, "this is just another hurdle that I had to get over...I had to pick myself up...I became harder probably, tougher and I've got a wall up, nothing gets through it, not even that (flood)." Indeed, despite losing almost all of her possessions and priceless personal memorabilia of her late husband, another woman displayed a narrative of strong resilience by separating the loss of items and possessions from ongoing life and survival and describing herself as "very fortunate." Over half (6 of 10) related their recent flood exposure to their various past experiences with floods (including the 1955, 1974, and 2011 floods), with one recalling how he "was involved in evacuating people in 1974, we volunteered. So when 2011 came, I had a good idea, it was all sitting back in my mind, where all the floodwaters came to." Many of the participants described how they utilized this previous flooding experience to make decisions during the evacuation process when they felt they were starting to feel overwhelmed by the decisionmaking process and the lack of formal guidance. For example, one participant outlined how when he timed the fence posts going under and out of sight within 8 minutes, his previous experience with the 1974 floods prompted him that it was time to evacuate so he "got her (his wife) up on my shoulders... and we left."

The participants did comment on the dangers of relying too much on past experiences for guidance and reflection. For example, one man discussed that in 1974 he remembered people driving down the street with megaphones giving updates during the floods, and when he didn't see or hear anything "on the streets" in his neighborhood, he mistakenly believed (momentarily) that he and his wife may no longer have been at risk of the floodwaters. Despite this briefly identified risk, the participants who identified previous trauma (1974 floods, fires, deaths) all linked their narratives with these previous traumas when explaining how they coped (positively) with the floods. For example, these stories of past traumas were described matter-of-factly by residents and the recent floods were filed away as "just another experience."

\section{Resilience Theme 3: "Times are changing"-Sources of Support}

These older residents generally agreed that the nature of disasters had noticeably changed over recent years, with disasters increasing in number and seeming to disrupt communities to a greater extent. In discussing their flood experiences, they reflected on the changing face of society and social capital (Table 1). During the $1955(\mathrm{n}=2)$ and $1974(\mathrm{n}=6)$ floods, there was very little formal (linking and bridging) support from governments, nongovernmental organizations, or insurance companies, with one man recalling how in the 1974 floods you "just relied on your workmates to come and give you a hand to rebuild." Participants recalled how friends and neighbors banded together during the 1974 floods, sharing a strong sense of community spirit and support from friends and family during the crisis.

In comparison, there was a heavy reliance on "friendly strangers" (people who were not known to the participants, but part of the support networks/capital) in 2011 and 2013. In fact, the kindness of strangers (people completely outside the participants' social capital networks) was a hallmark of these 2 flood disasters. When participants did utilize the more formal forms of bridging or linking capital, some reported requiring a heavy dependence on their bonding network in order to understand and complete the lengthy paperwork required to engage with the services. This was reported when accessing insurance claims and government relief funds, both of which were unavailable in the 1974 floods. Some participants discussed avoiding accessing extra support from these more formal networks because of a lack of trust and unfamiliarity with the organizations and individuals working within the organization.

Participants reflected on the changing times of their social capital network and communication avenues. For example, as stated above, some stated that they had made individual phone calls for assistance, while younger family members used mass social media to receive information and recruit help. The participant narratives suggest that the use of social support for information gathering has evolved from a chat with the neighbors or people with megaphones walking the streets to the use of text messages, Facebook, and mass media. Many of the participants reported not engaging with these newer forms of technology and therefore not being able to receive or access necessary support and information throughout the flooding disaster.

\section{DISCUSSION}

The use of a combined qualitative methodology for this disaster research has provided a rich insight into how these 10 older adults experienced the 2011 and 2013 Brisbane floods as well as their recollection of past flood events in $1974(n=6)$ and $1955(\mathrm{n}=2)$. Consistent with a large body of research on resilience, ${ }^{33-35}$ these results highlight how older adults' post-flood resilience is not simply a one-dimensional trait but rather a complex multidimensional process involving individual characteristics (eg, age, previous experience) and social characteristics (eg, social support networks, social capital, family attachment) that intertwine to foster coping during and after a disaster.

First, this study highlighted the importance of social capital in relation to both the practical and psychological (resilience) needs of the older adults. Consistent with previous research on the development of resilience in older adults, $5,36,37$ bonding capital seemed to be especially relevant for logistical help and as a source of trusted information and 


\section{TABLE}

\begin{tabular}{|c|c|c|}
\hline & 1974 & $2011 / 2013$ \\
\hline Bonding capital & $\begin{array}{l}\text { Family } \\
\text { Neighbors } \\
\text { Workmates }\end{array}$ & $\begin{array}{l}\text { Family (some networks were cut due } \\
\text { to the nature of the flood disaster) }\end{array}$ \\
\hline Bridging capital & None reported & $\begin{array}{l}\text { Friendly strangers (or no one) } \\
\text { Red Cross, church groups }\end{array}$ \\
\hline Linking capital & $\begin{array}{l}\text { None reported } \\
\text { Little media (radio and newspaper) }\end{array}$ & $\begin{array}{l}\text { Politicians } \\
\text { Mass media (TV, social media) } \\
\text { Insurance representatives }\end{array}$ \\
\hline
\end{tabular}

assistance during and after the disaster. Many reported depending on this bonding capital for assistance evacuating, with bridging capital (specifically practical support from "friendly strangers") being instrumental in helping recovery during the immediate aftermath of the flood. Barton ${ }^{38}$ coined this large-scale response a "mass assault," where post-disaster community energies address the needs of victims. The need for strong social capital (and resulting practical support) during a disaster was highlighted by some participants who (albeit briefly, perhaps a reflection of their resilience) discussed the reality that flood-proofing their homes (moving furniture, sandbagging, storing valuables) was getting increasingly difficult owing to experiencing one of the most prominent symptoms or vulnerabilities of aging: deteriorating physical ability and mobility limitations. This is consistent with previous research, ${ }^{13,19,23}$ which suggests that effective preparation, evacuation, and practical response is influenced by social capital and social support.

Disasters can damage, weaken, or destroy tight bonding capital and force reliance on bridging capital, where loose connections across geographical, social, and cultural groups provide essential resources, support, and information. For example, during Hurricane Katrina, many people received help from church members, organizations, and total strangers. ${ }^{18,39}$ While bonding and bridging social capital provided assistance to many of these older adults, it is notable that a third reported no local family or friends, limited contact with neighbors, and generally being socially isolated within their community, which resulted in more negative experiences during and after the disaster. Indeed, Dynes ${ }^{20}$ noted that social isolation can trigger further dissociation or withdrawal from the community, learned helplessness, and heightened vulnerability, which is reflected in these results.

Linking social capital was weak, with none of these older adults reporting any positive or beneficial links to government representatives. This is reflected in disaster statistics, which show that older adults are more reluctant to engage with linking capital (social and government agencies) and therefore tend to underutilize official disaster assistance. ${ }^{39}$ Many actually distrusted officials, who were viewed as actively courting the media with no genuine interest in understanding or addressing residents' needs. Trust is also another common barrier in older adults developing strong linking capital with formal support services, as evidenced by the participants' narratives of not feeling comfortable accessing some services and relying on their bonding network to do so on their behalf. This is concerning because trust between agencies and community members is paramount to victims receiving, processing, and acting upon crucial support. ${ }^{25}$ Furthermore, the very nature of the disasters and the reliance on individuals (friendly strangers) outside of their social capital network could have been in direct contradiction to the preferences of many older adults in relation to the need for privacy, trust, and interaction. ${ }^{35}$

Compared to other age groups, older adults have a strong need for social capital throughout the disaster to mitigate the effects of stress and facilitate resilience, ${ }^{14,15}$ and the simple availability of bonding capital can be an important buffering factor for emotional health. ${ }^{34}$ The results of this paper support these prior findings-and the large body of research linking social support and capital to resilience and adaptive coping-as the participants who reported more difficult emotional recoveries also reported feeling isolated due to low social capital.

Second, these results challenge the automatic assumption that older adults are vulnerable, suggesting that a lifetime of experience might actually foster resilience in the face of adversity. Given the generational experiences of this age group (including surviving traumas such as World War II, economic depression, and numerous natural disasters), these participants had developed a wealth of strategies for coping with the challenges of the floods. In fact, our results are consistent with a large body of evidence from the literature on resilience which suggests that previous experience (and resulting resilient outcome) acts as a buffer against future disaster risk. ${ }^{34}$ Like Ferraro's ${ }^{14}$ study of older adults who survived the 1997 Grand Forks floods, our findings are suggestive of stress inoculation: repeated exposure to flooding disasters may have acted as a psychological buffer, fostering resilience during disaster. The participants in this research 
who displayed resilient narratives relating to their prior experiences tended to appraise the flooding situation positively (ie, more manageable) and were better able to cope psychologically. These results support the suggestion by the World Health Organization ${ }^{40}$ that older adults proactively utilize their previous trauma or disaster experience and survival know-how to help them to cope, which can also work to provide psychological inspiration and both emotional and practical guidance to others. This suggestion from the World Health Organization and the results of this study challenge the traditional "narrative of decline" label placed on many older adults, while also still recognizing the need for the identification of any possible vulnerabilities.

Third, increasing numbers of older adults are choosing to age in place, living independently in their own homes for longer. This independence and desire to not be a burden, which is further encouraged by Australia's disaster management policy, may lead to a decrease in extended social capital networks. Hence, the impact of these reduced networks may mean that older adults struggle with maintaining effective coping as traditional forms of social capital (family and friends) become less available due to the very nature of floods, which may result in vehicle and telephone access being cut and support networks being unavailable. Research by Meyer ${ }^{41}$ found that many older adults assume that family members will support each other in disasters, with $36 \%$ identifying family members as their only source of capital during disasters. Interventions solely aimed at increasing this bonding capital can actually be fraught with danger because by increasing the density of these relationships, an older adult may be less likely to reach out to individuals not in the network, which may fragment them further from the community. With Australia's disaster management policy emphasizing a self-help approach, this study highlights the value of proactively strengthening bridging and linking capital within communities as a resource designed to support more vulnerable community members during disasters. Because the proportion of older community-dwelling adults potentially requiring assistance during a disaster is likely to increase, the need to strengthen these networks is also of growing importance.

\section{CONCLUSIONS}

The findings of this research need to be interpreted within the study limitations. The study sample consisted of a relatively small number of participants from one community, with limited socioeconomic diversity. However, despite this limitation, natural disasters are a harsh reality for Australia and these older adults' stories of disaster recovery and resilience are important in terms of operating as a counternarrative to displace the dominant "narrative of decline" within Western society. ${ }^{38}$ Future climate change predictions highlight the need to build strong and healthy resilient communities that can not only withstand but positively recover from natural disasters. Furthermore, the very nature of the changes in Australian disaster management policy, including a shift in public response and social capital to one of "friendly strangers" and more formalized support systems, highlights the need to develop bridging and linking capital by encouraging the formation of new networks as a means of improving overall resilience. By drawing attention to how social capital can strongly influence an older person's relative vulnerability or resilience during a disaster, this research emphasizes the importance of initiatives that enhance social cohesion, trust, and social capital within local communities. Given the limited literature on older adults' disaster experiences, this article is significant in exploring the challenges older adults face in times of disaster while also highlighting their stories of resilience.

\section{About the Authors}

School of Design, Creative Industries Faculty, Queensland University of Technology, Brisbane, Australia.

Correspondence and reprint requests to Lauren Brockie, School of Design, Creative Industries Faculty, Queensland University of Technology, 2 George St, Brisbane, Australia 0413048255 (e-mail: laurenbrockie@bigpond.com).

\section{Acknowledgments}

This research was undertaken as part of the primary author's PhD research. The primary author was awarded an Australian Postgraduate Award Scholarship and a Queensland Smart Futures Scholarship.

Published online: January 18, 2017.

\section{REFERENCES}

1. Huggins TJ, Peace R, Hill SR, et al. Visually modelling collaborative research into innovative community disaster resilience practice, strategy and governance. Int J Disaster Risk Science. 2015;6(3):282-294. http://dx. doi.org/10.1007/s13753-015-0061-6.

2. Teo M, Goonetilleke A, Ziyath A. An integrated framework for assessing community resilience in disaster management. In: Barnes $\mathrm{P}$, Goonetilleke A, eds. Proceedings of the 9th Annual International Conference of the International Institute for Infrastructure Renewal and Reconstruction (8-10 July 2013). Brisbane, Australia: Queensland University of Technology; 2015:309-314.

3. Powell S, Plouffe L, Gorr P. When ageing and disasters collide: lessons from 16 international case studies. Radiat Prot Dosimetry. 2009; 134(3-4):202-206. http://dx.doi.org/10.1093/rpd/ncp082.

4. Tuohy R, Stephens C. Exploring older adults' personal and social vulnerability in a disaster. Int J Emerg Manag. 2011;8(1):60-74. http://dx. doi.org/10.1504/IJEM.2011.040399.

5. Adams V, Kaufman S, Van Hattum T, et al. Aging disaster: mortality, vulnerability, and long-term recovery among Katrina survivors. Med Anthropol. 2011;30(3):247-270. http://dx.doi.org/10.1080/01459740.2011.560777.

6. Commonwealth of Australia. National Strategy for Disaster Resilience. Canberra Commonwealth of Australia; 2011.

7. Allen R, Philip H, Harris G, et al. Resilience: Definitions, Ambiguities and Applications. In: Resnick B, Gwyther L, Roberto K, eds. Resilience in Aging: Concepts, Research, and Outcomes. New York: Springer Publishing; 2011:1-14.

8. Seery M, Holman E, Silver R. Whatever does not kill us: cumulative lifetime adversity, vulnerability, and resilience. J Pers Soc Psychol. 2010;99(6):1025-1041. http://dx.doi.org/10.1037/a0021344.

9. Wiles J, Wild K, Kerse N, et al. Resilience from the point of view of older people: 'There's still life beyond a funny knee, Soc Sci Med. 2012; 74(3):416-424. http://dx.doi.org/10.1016/j.socscimed.2011.11.005 
10. Cook J. Traumatic exposure and PTSD in older adults: introduction to the special issue. J Clin Geropsychol. 2002;8(3):149-152. http://dx.doi.org/ 10.1023/A:1015997209635.

11. Knight B, Gatz M, Heller K, Bengtson V. Age and emotional response to the Northridge earthquake: A longitudinal analysis. Psychol Aging. 2000;15:627-634.

12. Norris F, Byrne C, Diaz E, et al. Psychosocial resources in the aftermath of natural and human-caused disasters: A review of the empirical literature, with implications for intervention. http://www.ncptsd.va.gov/ ncmain/ncdocs/fact_shts/fs_resources.htmel?printable-template=factsheet. Published 2007. Accessed March 16, 2014.

13. Touhy R, Stephens C, Johnston D. Older adults' disaster preparedness in the context of September 2010-December 2012 Canterbury earthquake sequence. Int J Disaster Risk Reduct. 2014;9:194-203.

14. Ferraro F. Psychological resilience in older adults following the 1997 flood. Clin Geropsychol. 2003;26:139-144.

15. Touhy R, Stephens C. Older adults' narratives about a flood disaster: resilience, coherence, and personal identity. J Aging Stud. 2012;26(1):26-34.

16. Hawkins R, Maurer K. Bonding, bridging and linking: how social capital operated in New Orleans following Hurricane Katrina. Br J Social Work. 2010;40(6):1777-1793.

17. Portes A. Social capital: its origins and applications in modern sociology. Annu Rev Sociol. 1998;24:1-24.

18. Aldrich D. Building Resilience: Social Capital in Post-Disaster Recovery. Chicago: University of Chicago Press; 2012.

19. Fussell E. Leaving New Orleans: Social Stratification, Networks, and Hurricane Evacuation. http://understandingkatrina.ssrc.org/Fussell/. Published June 11, 2006. Accessed October 31, 2016.

20. Dynes R. Social capital: dealing with community emergencies. Homeland Security Affairs. 2006;2(2):1-26.

21. Adler P, Kwon S. Social capital: prospects for a new concept. Acad Manage Rev. 2002;27(1):17-40.

22. McPherson M, Smith-Lovin L, Cook J. Birds of a feather: homophily in social networks. Annu Rev Sociol. 2001;27(1):415-444.

23. Small ML. Unanticipated Gains: Origins of Network Inequality in Everyday Life. New York: Oxford University Press; 2010.

24. Elliot J, Haney T, Sams-Abiodun P. Limits to social capital: comparing network assistance in two New Orleans neighbors devastated by Hurricane Katrina. Sociol Q. 2010;51:624-648.

25. Durant T. The utility of vulnerability and social capital theories in studying the impact Hurricane Katrina on the elderly. J Fam Issues. 2011;32(10):1285-1302.
26. Nakagawa Y, Shaw R. Social capital: a missing link to disaster recovery. Int J Mass Emerg Disasters. 2004;22:5-34.

27. Charmaz K. Constructing Grounded Theory: A Practical Guide Through Qualitative Analysis. London: Sage; 2006.

28. Riessman C. Narrative Methods for the Human Sciences. Los Angeles, CA: Sage Publishing; 2008.

29. Lal S, Suto M, Ungar M. Examining the potential of combining the methods of grounded theory and narrative inquiry: a comparative analysis. Qual Rep. 2012;17:1-22.

30. Australian Bureau of Statistics (ABS). Census Quick Stats: Ipswich (SA4). 2011. http://www.censusdata.abs.gov.au/census_services/getproduct/ census/2011/quickstat/310?opendocument\&navpos=220. Accessed October 31, 2016.

31. Apelt C. January 2011 Flood Event - Report on the operation of Somerset Dam and Wivenhoe Dam. St Lucia, Australia: Uniquest Pty Ltd; 2011.

32. Bureau of Meteorology. Known floods in the Brisbane and Bremer river basin. http://www.bom.gov.au/qld/flood/fld_history/brisbane_history.shtml. January 2014.

33. Bonanno G. Clarifying and extending the construct of adult resilience. Am Psychol. 2005;60:265-267.

34. Masten A. Ordinary Magic: Resilience in Development. New York: Guilford Press; 2014.

35. Stanko K, Cherry K, Ryker K, et al. Looking for the silver lining: benefit finding after hurricanes Katrina and Rita in middle-aged, older and oldest-old adults. Curr Psychol. 2015;34:564-575.

36. Norris F, Stevens S, Pfefferbaum B, et al. Community resilience as a metaphor, theory, set of capacities, and strategy for disaster readiness. Am J Community Psychol. 2008;41:127-150.

37. Aldrich DP, Meyer AM. Social capital and community resilience. Am Behav Sci. 2014;59:254-269.

38. Barton A. Communities in Disaster: A Sociological Analysis of Collective Stress Situations. New York: Doubleday; 1969.

39. Henderson T, Roberto K, Kamo Y. Older adults' responses to Hurricane Katrina: daily hassles and coping strategies. J Appl Gerontol. 2009; 29:48-64.

40. World Health Organization. Older persons in emergencies: an active ageing perspective. Geneva, Switzerland: World Health Organization; 2008.

41. Meyer M. Social capital and collective efficacy for disaster resilience: Connecting individuals with communities and vulnerability with resilience in hurricane-prone communities in Florida [dissertation]. Fort Collins: Colorado State University; 2013. 